\title{
Comparison of Antibacterial Effects of Photodynamic Therapy and an Irrigation Activation System on Root Canals Infected With Enterococcus faecalis: An In Vitro Study
}

\author{
Mohammad Asnaashari', Niloufar Kooshki², Mohammad Mahdi Salehii ${ }^{3}$, Saranaz Azari-Marhabi ${ }^{*}$, Hedieh \\ Amin Moghadassi ${ }^{4}$
}

${ }^{1}$ Laser Application in Medical Sciences Research Center, Shahid Beheshti University of Medical Sciences, Tehran, Iran ${ }^{2}$ DDS, Laser Application in Medical Sciences Research Center, Shahid Beheshti University of Medical Sciences, Tehran, Iran ${ }^{3}$ Dental students' research committee, faculty of dentistry, Isfahan University of Medical Sciences, Isfahan, Iran ${ }^{4}$ Research Assistant, Chronic Respiratory Diseases Research Center (CRDRC), National Research Institute of Tuberculosis and Lung Diseases (NRITLD), Shahid Beheshti University of Medical Sciences, Tehran, Iran

\author{
*Correspondence to \\ Saranaz Azari-Marhabi, \\ Email: dr.s.azari@sbmu.ac.ir, \\ saranazazari@yahoo.com \\ Published online June 21, 2020
}

\begin{abstract}
Introduction: Enterococcus faecalis is a resistant bacterium which is the most abundant species in infected root canals. Photodynamic therapy (PDT) is a method for killing the bacteria with active Oxygen radicals generated in a photosensitizer when exposed to centralized light. Furthermore, as a new method of canal disinfection, a variety of irrigation activation systems have been introduced, one of which is GentleFile (GF) with rotary movements and spiral effects for antibacterial action. This study aimed to compare the effectiveness of the two mentioned methods when used with and without Sodium Hypochlorite in eliminating E. faecalis from infected root canals.

Methods: Fifty-eight uniradicular teeth were randomly divided into 4 experimental groups of 14 . Two specimens were selected for later scanning electron microscopy in order to screen the procedure steps. In each experimental group, 10 samples were selected to be treated with GF or PDT; 3 of them were selected as positive controls and the other one sample was chosen as a negative control. Experimental groups were as follows: (1) Irrigation activation system, (2) Irrigation activation system + sodium hypochlorite, (3) PDT, and (4) PDT+ sodium hypochlorite. The specimens were then cultured for a bacterial colony count.

Results The decrease in the bacterial count after the treatment with the irrigation activation system was 99.8\% $(P=0.011)$ and when the system was used with sodium hypochlorite, it was $100 \%(P=0.001)$. The antibacterial effect of PDT was $90.08 \%(P=0.011)$ and it was $99.7 \%$ when PDT was combined with sodium hypochlorite $(P=0.011)$.

Conclusion: All four methods can be administered as complementary methods in root canal disinfection. According to the results of disinfection in the experimental groups of current study it is concluded that integration of new technologies such as activation irrigation system or PDT in Combination with $\mathrm{NaOCl}$ ameliorates disinfection of root canal and can provide several advantages in the endodontic outcome.

Keywords: Enterococcus faecalis; Photodynamic therapy; GentleFile; Irrigation activation system; Sodium hypochlorite.
\end{abstract}

\section{Introduction}

Insufficient disinfection of the root canal system results in treatment failure and thus prevents the healing of apical periodontitis. ${ }^{1}$ According to previous studies, the deep penetration of microorganisms into complex anatomical regions such as lateral canals, apical deltas, dentinal tubule constrictions and into the smear layer decreases the efficacy of the common irrigation. ${ }^{2-4}$ In addition, several studies indicated that even after a thorough endodontic treatment, there is a chance of failure due to resistant bacteria remaining in root canal systems. ${ }^{3,5-7}$

Enterococcus faecalis is a gram-positive anaerobic coccus which is the most abundant species in root canals, causing primary or secondary infections. ${ }^{8,9}$ This bacterium shows resistance to dressings such as calcium hydroxide and to irrigators through biofilm formation, deep penetration into dentinal tubules, and hydrogen-active components in its plasma membrane. ${ }^{10-12}$

Sodium hypochlorite $(\mathrm{NaOCl})$ is a commonly used irrigant, dissolving debris and necrotic tissues. ${ }^{13}$ Its

Please cite this article as follows: Asnaashari M, Kooshki N, Salehi MM, Azari-Marhabi S, Amin Moghadassi H. Comparison of antibacterial effects of photodynamic therapy and an irrigation activation system on root canals infected with Enterococcus faecalis: an in vitro study. J Lasers Med Sci. 2020;11(3):243-248. doi:10.34172/jlms.2020.41. 
dentinal penetration depth is $60-150 \mu \mathrm{m}$ while $E$. faecalis has been detected $1200 \mu \mathrm{m}$ inside dentinal tubules. ${ }^{10}$

A new method introduced for canal disinfection and eliminating pathogenic bacteria is photodynamic therapy (PDT). In this method, light absorption in a photosensitizer causes the generation of active oxygen radicals and the destruction of microorganisms. ${ }^{14-16}$ There are 3 main components in PDT: a photosensitizer, centralized light or laser, and oxygen; methylene blue photosensitizer is a hydrophilic phenothiazine derivative with light absorption at $660 \mathrm{~nm}$. This maximum lies well within the emission range of common diode lasers used for PDT. ${ }^{17}$ Methylene blue is able to pass the protein channels in gram-negative bacteria's plasma membrane. It has shown the capability of destroying $83 \%$ of E. faecalis bacteria inside a canal if used alone and $97 \%$ of E. faecalis in biofilms if used with red light exposure. ${ }^{18,19}$

A variety of techniques and irrigant delivery devices have been introduced for more effective canal disinfection following cleaning and shaping. ${ }^{20} \mathrm{~A}$ newly introduced irrigation activation system known as GentleFile (Medic NRG, Kibbutz Afikim, Israel) is a rotary system with improved mechanical properties. The single-use stainless steel files that abrade/scrape the dentinal walls are operated by a fully automated handpiece at a maximum speed of 6500 RPM.

The pecking motion of the files causes a spiral effect on the irrigant, making the antibacterial effect stronger. ${ }^{21}$

The present study aimed to compare the effectiveness of an irrigation activation system (Gentlefile) and PDT in eliminating $E$. faecalis from infected canals.

\section{Materials and Methods}

Specimen Preparation

Fifty-eight freshly extracted, intact, adult uniradicular human teeth were collected. They were placed in $\mathrm{NaOCl}$ $5.25 \%$ and then stored in sterile saline $0.9 \%$ at room temperature. Tooth crowns were cut with a disk bur so that all canals reached the standard working length (WL) of $14 \mathrm{~mm}$. The WL was determined by introducing a K-file \#15 (Dentsply/Maillefer/Tulsa/OK) in the canal until its tip was visualized at the apical foramen. Then, the canals were sequentially prepared within the $0.5 \mathrm{~mm}$ apical end of the canal via the crown-down instrumentation technique up to master apical file size 40 with a rotary file (Protaper, sx,s1,s2,f1,f2) (Dentsply/Maillefer/Tulsa/OK) under irrigation with $2 \mathrm{cc}$ of $\mathrm{NaOCl} 2.25 \%$.

Two specimens were selected for later scanning electron microscopy in order to screen the procedure steps. They were then cut in half using a disk bur.

Since the smear layer inhibits the contamination of tubules by E. faecalis, the teeth were placed in EDTA (ethylenediaminetetraacetic acid) $17 \%$ in a vortex instrument for 15 minutes to remove the smear layer.

Then, they were irrigated with normal saline and placed in $\mathrm{NaOCl} 2.25 \%$ in a vortex instrument for 10 minutes. Afterward, the canals were dried out using absorbent paper points and the apical foramina were sealed by a composite resin (Denfil, South Korea) under a biologic hood.

Each tooth was transferred into a lab tube containing sterile Phosphate-buffered solution (Germany, Merk). Then, the teeth were sterilized in an autoclave for 15 minutes at $121^{\circ} \mathrm{C}$.

The teeth were randomly divided into 4 experimental groups of 14. In each group, 13 teeth were later infected with E. faecalis, 3 of them were selected as positive controls and 10 samples were selected to be treated with GF or PDT; the other one sample was chosen as a negative control not to be infected or to receive any kind of treatment (Figure 1).

\section{Bacterial Culturing}

A frozen pool of E. faecalis was administered for this purpose. The E. faecalis frozen bacterium (Accession number: ATCC9854) was transferred to Broth Hewitt Todd agar plate and was incubated for 24 hours at a temperature of $37^{\circ} \mathrm{C}$. Single colonies were inoculated to a $10 \mathrm{ml}$ BHA medium and were incubated for 24 hours at a temperature of $37^{\circ} \mathrm{C}$. Then, a $1.5 \times 10^{8} \mathrm{CFU} / \mathrm{mL}$ suspension which equals $0.5 \mathrm{McF}$ arland was prepared. In order to have a $0.5 \mathrm{McF}$ arland sample, light absorption between $0.08-0.1$ is needed in spectrophotometry with a wavelength of $600 \mathrm{~nm}$.

Each tooth was placed in a sterile test tube, with $1 \mathrm{~mL}$ of the prepared E. faecalis bacterial suspension and BHA

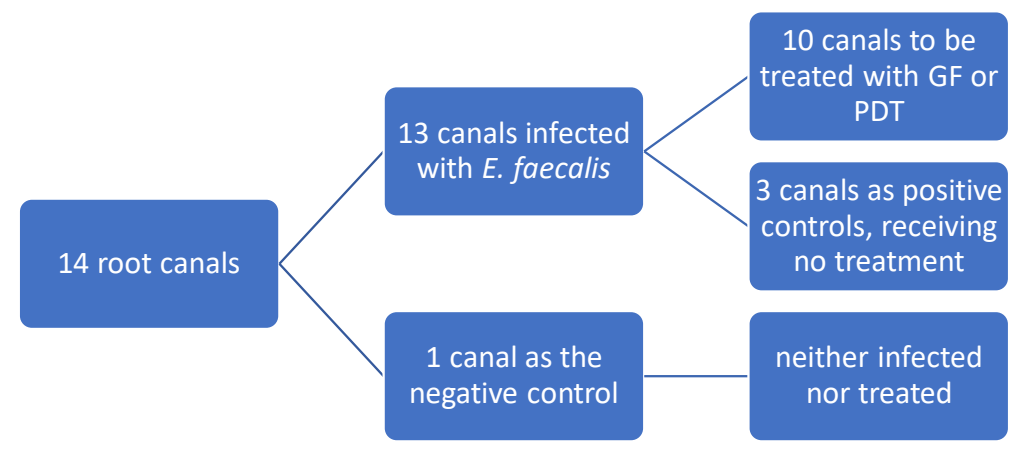

Figure 1. Divisions Inside Each of the 4 Groups With 14 Canals. 
medium (Merck, Germany).

For deeper bacterial penetration into the dentinal tubules and for biofilm formation, the samples were incubated in anaerobic conditions at a temperature of $37^{\circ} \mathrm{C}$ for 21 days. The medium was replaced every two days with a fresh medium. During this period, some of the samples were randomly selected and cultured on a BHA medium for 24 hours in an incubator in order to make sure about the bacterial growth of the samples or their not being infected. This was carried out every 7 days.

Specimen Preparation for Scanning Electron Microscopy The scanning electron microscopy (SEM) specimens were treated in the same way as the other samples were. A specimen underwent $E$. faecalis culturing for 21 days as the positive control and the other, as the negative control, was sterilized in an autoclave. Both the specimens were then placed in glutaraldehyde $2.5 \%$ in $4^{\circ} \mathrm{C}$ for 24 hours for fixation. They were washed with distilled water for 30 seconds and finally, sent for electron microscopy. The positive control was sent for electron microscopy to make sure of biofilm formation and the negative control underwent this procedure to make sure of the accuracy of the sterilization procedure.

\section{Cleaning}

After the 21-day period of incubation, the instrumentation was accomplished under a biologic hood under sterile conditions.

Each sample was taken out of its test tube and washed with $5 \mathrm{~mL}$ of sterile saline. In the first group, the pulp canals were irrigated with $100 \mu \mathrm{L}$ of sterile saline and then instrumented using the irrigation activation system, Gentlefile. The system was used for 1 minute and was in contact with the canal walls. A \#25 file was introduced in each canal within $1 \mathrm{~mm}$ of the WL with an up and down movement. The canal was then irrigated using $5 \mathrm{ml}$ of sterile saline.

In the second group, $100 \mu \mathrm{L}$ of $\mathrm{NaOCl} 2.25 \%$ was injected in each canal and remained for 1 minute. The canal was then irrigated using $5 \mathrm{ml}$ of sterile saline and instrumented using the irrigation activation system

In the third group, the teeth were treated with PDT with methylene blue. $100 \mu \mathrm{L}$ of methylene blue $25 \mu \mathrm{g} / \mathrm{mL}$ was injected in each canal followed by diode laser emission inside the canal. The Konftec Laser device (Taiwan) with a wavelength of $660 \mathrm{~nm}, 150 \mathrm{~mW}, 60$ second irradiation and 9-joule energy was used according to the manufacturer's manual.

The system was coupled to an optical fiber with a diameter of $200 \mu \mathrm{m}$. The optical fiber was initially placed $1 \mathrm{~mm}$ shorter than WL, and spiral movements, from apical to cervical, were performed to allow adequate distribution of the light throughout the root canal (stepback technique). Each exposure took 60 seconds (20 seconds of exposure followed by a 10 -second pause), repeated three times. The canals were then irrigated with sterile saline.

In the fourth group, $100 \mu \mathrm{L}$ of $\mathrm{NaOCl} 2.25 \%$ was injected in each canal and remained for 1 minute initially. The canals were then irrigated with $5 \mathrm{~mL}$ of sterile saline and treated with PDT.

\section{Sampling}

Immediately after the cleaning stage, a sterile Protaper F3 file was introduced for 30 seconds in each canal for sampling. The Protaper file was then vortexed in a lab tube containing $10 \mathrm{~mL}$ of normal saline.

\section{Sample Culturing}

The vortexed saline inside the tube was a 10 -fold serial dilution in multiple tubes. $100 \mu \mathrm{L}$ of the diluted solutions were cultured in $8^{\star} 8 \mathrm{~cm}$ plates containing $\mathrm{BHA}$ with spread technique. Then, the cultures were placed in a $37^{\circ} \mathrm{C}$ incubator for 24 hours.

All the procedures above were carried out under a biologic hood to achieve sterile conditions.

Counting the colony-forming units (CFU) of E. faecalis $(\mathrm{CFU} / \mathrm{mL})$ was carried out using a colony counter system (Tayf Azma, Iran).

\section{Statistics}

The gathered data on bacterial growth (CFU) was analyzed with the Mann-Whitney $U$ test using SPSS version 21 software.

\section{Results}

Counting the CFUs of E. faecalis (CFU/mL), using a colony counter system, revealed the data presented in Table 1.

In the second group, treated with $\mathrm{NaOCl}$ and the irrigation activation system, 0 CFUs were observed after treatment, and hence there was a reduction of $100 \%$ in the CFUs of E. faecalis $(P=0.001)$. The results in the other groups were not significantly different from one another. The reduction in CFUs was the minimum in the fourth group, treated with $\mathrm{PDT}$ only, with a $90.08 \%$ reduction in the CFUs $(P=0.011)$.

The SEM images revealed sterile negative control specimens (Figure 2A) and a suitably formed E. faecalis biofilm in positive control specimens (Figure 2A).

\section{Discussion}

Insufficient cleaning of the root canal system leads to failures in the root canal treatment and hinders the healing process of apical periodontitis.

Since the irrigants' efficacy depends on their close contact with the canal walls, the microorganisms penetrating the deeper layers of dentin will usually remain untouched. ${ }^{22}$ The aim of this study was to compare the antibacterial effect of PDT with an irrigation activator system on canals infected with E. faecalis in laboratory 
Table 1. The Number of CFUs of E. faecalis Before and After Each Treatment and the Reduction Percentage in CFUs

\begin{tabular}{|c|c|c|c|c|c|}
\hline Group Number & Treatment & CFUs Before Treatment & CFUs After Treatment & Percentage of Reduction in CFUs & $P$ Value \\
\hline 1 & Irrigation activation system & $4 \times 10^{7} \pm 5.5 \times 10^{6}$ & $8.7 \times 10^{4} \pm 4.8 \times 10^{4}$ & $99.8 \%$ & 0.011 \\
\hline 2 & Irrigation activation system $+\mathrm{NaOCl}$ & $2 \times 10^{5} \pm 1.4 \times 10^{5}$ & 0 & $100 \%$ & 0.001 \\
\hline 3 & PDT & $4 \times 10^{7} \pm 5.5 \times 10^{6}$ & $3.7 \times 10^{6} \pm 2.7 \times 10^{6}$ & $90.08 \%$ & 0.011 \\
\hline 4 & $\mathrm{PDT}+\mathrm{NaOCl}$ & $6 \times 10^{7} \pm 5.8 \times 10^{7}$ & $1.8 \times 10^{5} \pm 2.4 \times 10^{6}$ & $99.7 \%$ & 0.011 \\
\hline
\end{tabular}

conditions.

The irrigation activator system used in this study is a product of MIB Company, which has not been compared to PDT in any other studies. The results indicated that this system could be effective in eliminating the E. faecalis biofilm when used with $\mathrm{NaOCl}$. In addition, PDT was significantly effective in $E$. faecalis biofilm reduction when used with or without $\mathrm{NaOCl}$. The irrigation activation system showed the strongest antibacterial effect when used with $\mathrm{NaOCl}$. The second most effective method was PDT used in combination with $\mathrm{NaOCl}$, which was almost as effective as the irrigation system used without $\mathrm{NaOCl}$ ( PDT was performed after disinfection with sodium hypochlorite for further reduction of the E. faecalis bacteria), both stronger than PDT when applied without $\mathrm{NaOCl}$.

In the studies of Elumalai et al and Ragul et al on novel canal irrigation systems compared with conventional irrigation, it was observed that they facilitate conveyance of irrigants inside the canals in higher volumes and lead to higher effectiveness in canal debridement. ${ }^{23,24}$ The irrigation system used in our study removes the biofilm by functioning similar to rotary files and can improvise the disinfection effectiveness of the irrigant and thorough removal of microbes. ${ }^{24}$ Also, interestingly significant reduction of biofilm was observed in the irrigation activation system group without $\mathrm{NaOCl}$, which could be attributed to removing the infected dentin by abrading/ scraping of the dentinal walls by Gentlefile.

Siddiqui et al conducted a systematic review of 17 studies on the antibacterial effectiveness of PDT against E. faecalis in infected root canals and they reported that in 12 studies, PDT was successful in eliminating
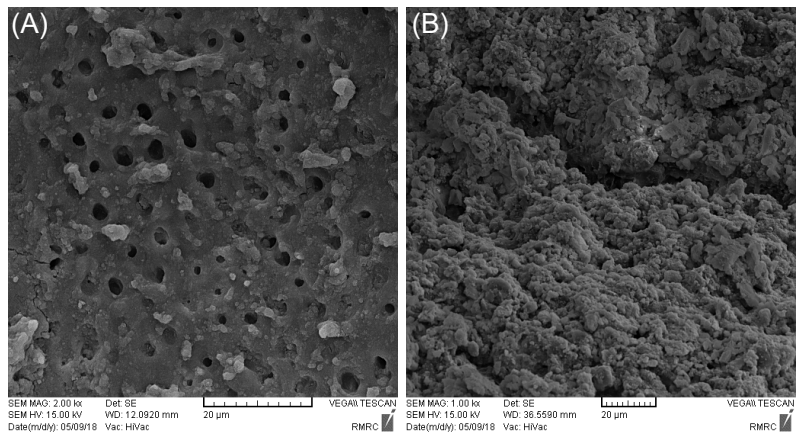

Figure 2. (A) SEM image of the negative control specimen. (B) SEM image of the positive specimen.
E. faecalis from infected root canals, in four studies, it was less efficient than conventional irrigation and instrumentation, and in one study, PDT was as effective as conventional endodontic irrigation and instrumentation. It was also reported that the intensity of PDT depends on the wavelength of the laser, its power, the exposure time, and the photosensitizer. In addition, in articles in which PDT was shown to be effective, the wavelengths used were between 600-805 $\mathrm{nm}$ and the photosensitizers were toluidine blue or methylene blue, which is in accordance with the results of our study. ${ }^{25}$

Fimple et al.observed that PDT with the same parameters of light and photosensitizer as those in our study resulted in an $80 \%$ decrease of the bacteria inside the canal. ${ }^{26}$ The bacterial reduction was $90.08 \%$ in our study.

In an experiment evaluating the effect of different energy levels, bacterial loads and different exposure cycles on the results of PDT, Soares et al administered the diode laser with a wavelength of $660 \mathrm{~nm}$ and a power of $40 \mathrm{~mW}$ along with methylene blue $50 \mu \mathrm{g} / \mathrm{mL}$. They found PDT very effective against bacteria. ${ }^{27}$

Similar to the results of our study, the results of a study by Hoedke et al revealed that the application of $\mathrm{NaOCl}$ with PDT improved its antibacterial function..$^{28}$

Souzo et al observed that $\mathrm{NaOCl}$ had a significantly better antibacterial function than PDT. A possible explanation may be the low concentration of Oxygen available for generating cytotoxic oxygen derivatives in the canal and particularly in the irregularities and dentinal tubules. The photosensitizer materials, in addition, may not penetrate these irregularities, ultimately resulting in the bacteria's remaining in these areas. They concluded that the antibacterial effect of PDT is restricted to areas accessed by $\mathrm{NaOCl}$ and depends on the penetration depth of the photosensitizer. They also observed that methylene blue and toluidine blue were not significantly different in PDT against E. faecalis. ${ }^{17}$

According to the results of the present study, complete eradication of the E. faecalis biofilm could be the result of this activation irrigation system in delivering and conveying $\mathrm{NaOCl}$ irrigant to the dental canal. The results of a systematic review by Nagendrababu et al regarding the effectiveness of ultrasonically activated irrigation in root canal disinfection revealed that the use of ultrasonically activation irrigation systems could result in superior microbial reduction within the root canal 
system compared to other types of irrigant activation and conventional syringe irrigation. ${ }^{29}$ However, according to the results of a clinical trial by Orozco et al, there was no significant difference between passive ultrasonic irrigation and conventional irrigation in decreasing bacterial counts. ${ }^{30}$ Furthermore, the results of a systematic review by Susila and Minu showed that the utilization of mechanical active irrigation devices is advantageous in root canal treatment. They stated that mechanical active irrigation devices are clinically efficient in the conveyance of the irrigant in the root canal, which leads to more cleanliness in root canals. ${ }^{31}$

Finally, it should be stated that GF Brush ${ }^{21}$ which improves the debridement of canals prepared with Gentlefile has also been introduced, but due to the limitations of sanctions in our country, it could not be accessible.

\section{Conclusion}

Within the limitations of the present study, it was concluded that both PDT and the irrigation activation system were significantly effective in decreasing CFU/ $\mathrm{mL}$. According to the results of disinfection in the experimental groups of current study it can be stated that integration of new technologies such as activation irrigation system or PDT in combination with $\mathrm{NaOCl}$ ameliorates disinfection of root canal and can provide several advantages in the endodontic outcome. They can be administered as complementary methods for root canal debridement and disinfection.

\section{Ethical Considerations}

Ethical approval was obtained from the research ethics committee of Shahid Beheshti University of Medical Sciences (IR.SBMU.RETECH.REC.1396.1118).

\section{Conflict of Interests}

The authors declare no conflict of interest.

\section{Acknowledgements}

This research was supported by a grant from Laser Application in Medical Sciences Research Center of Shahid Beheshti University of Medical Sciences.

\section{References}

1. Dianat O, SaediS, Kazem M, Alam M. Antimicrobial activity of nanoparticle calcium hydroxide against Enterococcus faecalis: an in vitro study. Iran Endod J. 2015;10(1):39-43.

2. Abdulla M, Ng Y, Gulabivala K, Moles DR, Spratt DA. Susceptibility of two Enterococcus faecalis phenotypes to root canal medicaments. J Endod. 2005;31(1):30-6. doi: 10.1097/01.don.0000136205.80807.5a.

3. Mohammadi Z. Chlorhexidine gluconate, its properties and applications in endodontics. Iran Endod J. 2008;2(4):11325.

4. Stuart CH, Schwartz SA, Beeson TJ, Owatz CB. Enterococcus faecalis: its role in root canal treatment failure and current concepts in retreatment. J Endod. 2006;32(2):93-8. doi: 10.1016/j.joen.2005.10.049.

5. Buck RA, Eleazer PD, Staat RH, Scheetz JP. Effectiveness of three endodontic irrigants at various tubular depths in human dentin. $J$ Endod. 2001;27(3):206-8. doi: 10.1097/00004770-200103000-00017.

6. Gordon W, Atabakhsh VA, Meza F, Doms A, Nissan R, Rizoiu I, et al. The antimicrobial efficacy of the erbium, chromium: yttrium-scandium-gallium-garnet laser with radial emitting tips on root canal dentin walls infected with Enterococcus faecalis. J Am Dent Assoc. 2007;138(7):9921002. doi: 10.14219/jada.archive.2007.0297.

7. Nageshwar Rao N, Kidiyoor H, Hegde C. Efficacy of calcium hydroxide-chlorhexidene paste against Enterococcus faecalis-an in vitro study. Endodontology. 2004;16:61-4.

8. Pinheiro ET, Gomes BP, Drucker DB, Zaia AA, Ferraz CC, Souza-Filho FJ. Antimicrobial susceptibility of Enterococcus faecalis isolated from canals of root filled teeth with periapical lesions. Int Endod J. 2004;37(11):75663. doi: 10.1111/j.1365-2591.2004.00865.x.

9. Peciuliene V, Reynaud AH, Balciuniene I, Haapasalo M. Isolation of yeasts and enteric bacteria in root-filled teeth with chronic apical periodontitis. Int Endod J. 2001;34(6):429-34. doi: 10.1046/j.1365-2591.2001.00411.x.

10. Bumb SS, Bhaskar DJ, Agali CR, Punia H, Gupta V, Singh $\mathrm{V}$, et al. Assessment of photodynamic therapy (PDT) in disinfection of deeper dentinal tubules in a root canal system: an in vitro study. JClin Diagn Res. 2014;8(11):ZC6771. doi: 10.7860/JCDR/2014/11047.5155.

11. Byström A, Sundqvist G. Bacteriologic evaluation of the efficacy of mechanical root canal instrumentation in endodontic therapy. Scand J Dent Res. 1981;89(4):321-8. doi: 10.1111/j.1600-0722.1981.tb01689.x.

12. Cha S, Park YS. Plasma in dentistry. Clin Plasma Med. 2014;2(1):4-10. doi: 10.1016/j.cpme.2014.04.002.

13. Prabhakar J, Senthilkumar M, Priya MS, Mahalakshmi K, Sehgal PK, Sukumaran VG. Evaluation of antimicrobial efficacy of herbal alternatives (Triphala and green tea polyphenols), MTAD, and 5\% sodium hypochlorite against Enterococcus faecalis biofilm formed on tooth substrate: an in vitro study. J Endod. 2010;36(1):83-6. doi: 10.1016/j. joen.2009.09.040.

14. Carvalho ES, Mello I, Albergaria SJ, Habitante SM, LageMarques JL, Raldi DP. Effect of chemical substances in removing methylene blue after photodynamic therapy in root canal treatment. Photomed Laser Surg. 2011;29(8):55963. doi: 10.1089/pho.2010.2922.

15. de Oliveira BP, Aguiar CM, Câmara AC. Photodynamic therapy in combating the causative microorganisms from endodontic infections. Eur J Dent. 2014;8(3):424-30. doi: 10.4103/1305-7456.137662.

16. Soukos NS, Wilson M, Burns T, Speight PM. Photodynamic effects of toluidine blue on human oral keratinocytes and fibroblasts and Streptococcus sanguis evaluated in vitro. Lasers Surg Med. 1996;18(3):253-9. doi: 10.1002/ (SICI) 1096-9101(1996)18:3<253::AID-LSM6>3.0.CO;2-R.

17. Souza LC, Brito PR, de Oliveira JCM, Alves FR, Moreira EJ, Sampaio-Filho HR, et al. Photodynamic therapy with two different photosensitizers as a supplement to instrumentation/irrigation procedures in promoting intracanal reduction of Enterococcus faecalis. J Endod. 
2010;36(2):292-6. doi: 10.1016/j.joen.2009.09.041.

18. Sen BH, Piskin B, Demirci T. Observation of bacteria and fungi in infected root canals and dentinal tubules by SEM. Endod Dent Traumatol. 1995;11(1):6-9. doi: 10.1111/ j.1600-9657.1995.tb00671.x.

19. Usacheva MN, Teichert MC, Biel MA. The interaction of lipopolysaccharides with phenothiazine dyes. Lasers Surg Med. 2003;33(5):311-9. doi: 10.1002/lsm.10226.

20. Urban K, Donnermeyer D, Schäfer E, Bürklein S. Canal cleanliness using different irrigation activation systems: a SEM evaluation. Clin Oral Investig. 2017;21(9):2681-7. doi: 10.1007/s00784-017-2070-x.

21. Neelakantan P, Khan K, Li KY, Shetty H, Xi W. Effectiveness of supplementary irrigant agitation with the Finisher GF Brush on the debridement of oval root canals instrumented with the Gentlefile or nickel titanium rotary instruments. Int Endod J. 2018;51(7):800-807. doi: 10.1111/iej.12892.

22. Mehrvarzfar P, Saghiri MA, Asatourian A, Fekrazad R, Karamifar K, Eslami G, et al. Additive effect of a diode laser on the antibacterial activity of $2.5 \% \mathrm{NaOCl}, 2 \% \mathrm{CHX}$ and MTAD against Enterococcus faecalis contaminating root canals: an in vitro study. J Oral Sci. 2011;53(3):355-60. doi: 10.2334/josnusd.53.355.

23. Elumalai D, Kumar A, Tewari RK, Mishra SK, Iftekhar H, Alam S, et al. Newer Endodontic irrigation devices: An update. J Dent Med Sci. 2014;13(6):4-8.

24. Ragul P, Dhanraj M, Jain AR. Irrigation technique used in cleaning and shaping during endodontic treatment - A review. Drug Invent Today. 2018;10(5):739-43.

25. Siddiqui SH, Awan KH, Javed F. Bactericidal efficacy of photodynamic therapy against Enterococcus faecalis in infected root canals: a systematic literature review. Photodiagnosis Photodyn Ther. 2013;10(4):632-43. doi: 10.1016/j.pdpdt.2013.07.006.

26. Fimple JL, Fontana CR, Foschi F, Ruggiero K, Song X, Pagonis TC, et al. Photodynamic treatment of endodontic polymicrobial infection in vitro. J Endod. 2008;34(6):72834. doi: 10.1016/j.joen.2008.03.011.

27. Soares JA, Soares SMCS, de Jesus Tavarez RR, de Castro Rizzi C, Vaz Rodrigues SCG, Maia Filho EM, et al. Exploring different photodynamic therapy parameters to optimize elimination of Enterococcus faecalis in planktonic form. Photodiagnosis Photodynamic Ther. 2018;22:127-31. doi: 10.1016/j.pdpdt.2018.03.009.

28. Hoedke D, Enseleit C, Gruner D, Dommisch H, Schlafer S, Dige I, et al. Effect of photodynamic therapy in combination with various irrigation protocols on an endodontic multispecies biofilm ex vivo. Int Endod J. 2018;51:e23-e34. doi: 10.1111/iej.12763.

29. Nagendrababu V, Jayaraman J, Suresh A, Kalyanasundaram S, Neelakantan P. Effectiveness of ultrasonically activated irrigation on root canal disinfection: a systematic review of in vitro studies. Clin Oral Investig. 2018;22(2):655-670. doi: 10.1007/s00784-018-2345-x.

30. Orozco EIF, Toia CC, Cavalli D, Khoury RD, da Rosa Cardoso FG, Bresciani E, et al. Effect of passive ultrasonic activation on microorganisms in primary root canal infection: a randomized clinical trial. J Appl Oral Sci. 2019;28:e20190100. doi: 10.1590/1678-7757-2019-0100.

31. Susila A, Minu J. Activated Irrigation vs. Conventional nonactivated irrigation in endodontics - a systematic review. Eur Endod J. 2019;3:96-110. doi: 10.14744/eej.2019.80774. 